\title{
Immunological Studies of the Human Placenta
}

\author{
CHARACTERIZATION OF IMMUNOGLOBULINS \\ ON TROPHOBLASTIC BASEMENT MEMBRANES
}

\author{
W. Page Faulk, M. Jeannet, W. D. Creighton, and A. Carbonara \\ From the MRC Rheumatism Unit, Canadian Red Cross Memorial Hospital, \\ Taplow, Maidenhead, Berkshire, England; Transplantation Immunology Unit, \\ Department of Medicine, University of Geneva, Geneva, Switzerland; WHO \\ Immunology Laboratory, Division of Haematology, Department of Medicine, \\ University of Geneva, Geneva, Switzerland; and the Institute of Medical \\ Genetics, University of Turin, Turin, Italy
}

A B S T R A C T Immunohistological and elution studies of the human placenta revealed the presence of IgG on the trophoblastic basement membrane (TBM) which demonstrated specificity for placental but not lung, thyroid, or kidney basement membranes, suggesting the presence of a placenta-specific antigen in TBM. IgG comprised the bulk of immunoglobulin in eluates, and small amounts of $\operatorname{IgA}$, trace amounts of $\operatorname{IgM}$, but no $\operatorname{IgE}$ or $\operatorname{IgD}$ were identified in eluates. The distribution of IgG subclasses in eluate was not unusual as compared to maternal and neonatal sera, and $\mathrm{Gm}$ and Inv typing of eluates indicated that it was of maternal origin. Small amounts of eluate-IgG effectively inhibited the blastogenic response of unrelated lymphocytes to old tuberculin, phytohemagglutinin, and in one- or two-way mixed lymphocyte culture reactions. The inhibition was distinct from nonspecific inhibitors, and dose-response analysis indicated that eluate was very much more potent as an inhibitor than were the nonspecific inhibitors. Inhibition was shown to not be due to anti-HL-A activity, and was probably not due to aggregated $\mathrm{IgG}$ or immune complexes. Binding of eluate to lymphocytes was very loose as shown by washing experiments, and no binding could be shown by immunofluorescence. The capacity of eluate IgG to inhibit MLC was retained after pepsin digestion to $F\left(a b^{\prime}\right)_{2}$, suggesting that the inhibition reactions were immunological. It is suggested that eluateIgG is maternal blocking antibody to a hitherto uncharacterized trophoblast antigen, and it is speculated that either abnormal antigen or aberrant responses to antigen could result in fetal wastage.

Received for publication 28 February 1974 and in revised form 3 June 1974.

\section{INTRODUCTION}

Propagation of the human species relies upon the biological grafting of the placenta to the maternal uterus during pregnancy and the uninterrupted contiguity of this homograft until delivery of the child. Billingham (1) has suggested that a great deal could be learned about transplantation if the mechanisms responsible for a successful placental graft were understood, and Medawar (2) has put forward several reasons for believing that these mechanisms are immunological. This concept has gained broad popular support, and Beer and Billingham (3) have recently reviewed most of the experimental work concerning immunobiological aspects of mammalian reproduction.

Mothers produce both humoral and cell-mediated immunity $(\mathrm{CMI})^{1}$ to fetal (paternal) and placental antigens during pregnancy. They produce antibodies to some proteins in fetal serum such as Gm (4) and Inv antigens (5), and their responses to erythrocyte and leukocyte antigens are well known. Rocklin, Zuckerman, Alpert, and David (6) have demonstrated CMI to neonatal lymphocytes by maternal lymphocytes using the macrophage migrationinhibition-factor (MIF) assay, and very similar results have been observed when maternal lymphocytes are incubated with placental antigens (7). There have been conflicting reports as to whether or not maternal CMI is

\footnotetext{
${ }^{1}$ Abbreviations used in this paper: CMI, cell-mediated immunity; FITC, fluorescein isothiocyanate; Ig, immunoglobulins; LALI, lymphocyte antibody lympholytic interaction; MIF, migration-inhibition factor; MLC, mixedlymphocyte culture; NHS, normal human serum; O. T., old tuberculin; PBS, phosphate-buffered saline; PEG, polyethylene glycol; PHA, phytohemagglutinin; TBM, trophoblastic basement membrane.
} 
depressed during pregnancy $(8,9)$, but Ceppellini et al. (10) have shown a degree of selective unresponsiveness between maternal and neonatal lymphocytes. The role of serum blocking factors to CMI reactions also seems to be important in pregnancy because such factors have been identified in both maternal $(11,12)$ and neonatal (13) plasma as well as in extracts of certain placental glycoproteins (14). These factors can block both mixedlymphocyte-culture (MLC) and MIF reactions (15).

Our investigations have focused on the human placenta as this is the principal site of contact and exchange in the maternofetal relationship (16). Antigens in human placentas are not well characterized. There is evidence that trophoblastic basement membranes (TBM) are antigenically similar to glomerular basement membrane, and common antigens are demonstrable in the mitochondrial and microsomal fractions of trophoblasts and renal proximal tubular epithelium (3).

Sensitization of maternal lymphocytes to placental antigens during pregnancy suggests that placentas may produce organ-specific antigens, and the removal of toxic properties from antitrophoblast serum by absorption with lymphocytes (17) suggests that there may be antigens common to trophoblasts and lymphocytes. HL-A antigens have been reported to be present on trophoblasts in vitro (18), but it has been suggested that these antigens are masked in vivo (19).

Direct immunohistological evidence that the placenta may be a site of immunological activity in humans was presented by McCormick et al. (20) when they demonstrated $\mathrm{IgG}$, complement, and fibrinogen on TBM. They were able to elute IgG from TBM, and such placental eluates have been subsequently shown to inhibit several blastogenic reactions by human lymphocytes in culture (21-25). The purpose of the present paper is to present the results of our immunological studies of immunoglobulins (Ig) on TBM of human placentas, as these seem to represent clear evidence of immunological reactions occurring within placentas. The results of these investigations suggest a concept that has not been hitherto considered in the immunobiology of pregnancy in humans.

\section{METHODS}

Tissues. 20 normal full-term placentas were studied. These were obtained immediately upon delivery and were perfused with chilled Krebs' saline. Blocks of tissues were obtained from the midportion of the central cotyledon and quick-frozen in a mixture of solid $\mathrm{CO}_{2}$ and acetone, and 4$\mu \mathrm{m}$ sections for immunofluorescence studies were cut in a cryostat.

Elution of tissucs. Each placenta was minced into small squares not exceeding $1.0 \mathrm{~cm}^{2}$ and washed repeatedly by stirring with phosphate-buffered saline (PBS) at $5^{\circ} \mathrm{C}$ until the washings were protein-free as judged by optical density readings at $280 \mathrm{~nm}$ in a spectrophotometer. The washed material was then placed in at least a 2 -vol excess of pre- warmed $0.1 \mathrm{M}$ citric acid buffer, $\mathrm{pH} 2.7$, at $37^{\circ} \mathrm{C}$ for $1 \mathrm{~h}$. The $\mathrm{pH}$ was monitored throughout the elution procedure and additional citric acid was added as required to maintain a $\mathrm{pH}$ value of 2.7 . The solution was then centrifuged at $2,000 \mathrm{rpm}$ for $30 \mathrm{~min}$ at $5^{\circ} \mathrm{C}$ and the supernate was decanted and readjusted to $\mathrm{pH} 7.4$ with solid Tris. Eluates were concentrated by ultrafiltration, redialyzed against PBS, and stored at $-20^{\circ} \mathrm{C}$ until use.

Antisera. Antisera to human Ig classes were obtained through the courtesy of the WHO International Reference Centre for Immunoglobulins, Lausanne, Switzerland, and the WHO International Reference Centre for Autoimmune disorders, London. The Autoimmune Centre also provided antisera to IgG subclasses, specificity checks for which have been previously reported (26). An anti-normal human serum (NHS) was prepared by the immunization method of the Medical Research Council (27). Antisera used in the $\mathrm{Gm}$ and Inv typing have been previously described (28).

Techniques. Standard methods were used in all cases. This is true for immunoelectrophoresis, Ouchterlony testing, Mancini single-radial diffusion analysis (29), IgG subclass typing (26), Gm and Inv typing (28), DEAE-cellulose chromatography, and pepsin hydrolysis (29). Antisera were labeled with fluorescein isothiocyanate (FITC) by a dialysis technique (30), chromatographed with DEAEcellulose (31), and subjected to staining reactions and specificity checks as previously described (32). Sections were examined by using transmitted light from a halogen lamp and FITC-interference filters in a Reichert microscope. Tests of solubility in polyethylene glycol (PEG) were done according to Creighton, Lambert, and Miescher (33).

Lymphocytes were obtained by Ficoll-Hypaque flotation and one-way MLC reactions (34) consisted of $5 \times 10^{5}$ responding and an equal number of mitomycin-treated stimulator lymphocytes in $1.0 \mathrm{~m}$ TC 199 medium with HEPES buffer. Penicillin, streptomycin, and $20 \%$ cell-free serum obtained from pooled human AB sera were added to the culture medium. The same medium was used for two-way MLC reactions and blastogenic tests with old tuberculin (O. T.) and phytohemagglutinin (PHA). Preliminary dose-response experiments were done to determine optimum amounts of O. T. and PHA, and thereafter all test samples were cultured in triplicate. After $96 \mathrm{~h}$ of culture (PHA) $2 \mu \mathrm{Ci}$ of tritiated thymidine were added and the cultures harvested 16-18 h later. Cultures with $\mathrm{O}$. $\mathrm{T}$. were grown $120 \mathrm{~h}$ and then pulsed $10 \mathrm{~h}$ with tritiated thymidine (10). The lymphocytes were treated with trichloroacetic acid, solubilized, and counted in a liquid scintillation spectrometer. Results are expressed in counts per minute plus-orminus the standard error of the mean.

The lymphocyte antibody lympholytic interaction (LALI) assay was performed according to the technique described by Trinchieri, Bernoco, Curtoni, Miggiano, and Ceppellini (35). ${ }^{51} \mathrm{Cr}$-labeled lymphocytes $\left(2 \times 10^{4}\right)$ are incubated $\frac{1}{2} \mathrm{~h}$ at room temperature with inactivated placenta eluates and then peripheral blood lymphocytes $\left(10^{\circ}\right)$ from a normal donor are added. After an additional 4-h incubation at $37^{\circ} \mathrm{C}$ specific ${ }^{51} \mathrm{Cr}$ release is measured and expressed in counts per minute over spontaneous release.

\section{RESULTS}

\section{Immunohistological studies}

Results of experiments using immunofluorescence on cryostat sections of fresh, perfused, human placentas 


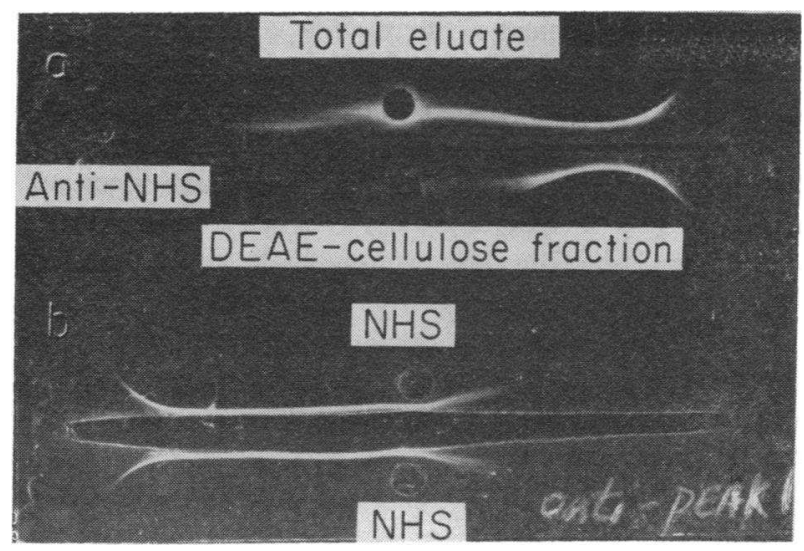

FIgURE 1 Immunoelectrophoresis of placental eluate and of antibody to placental eluate. (a) Top well contained unfractionated eluate, second well contained DEAE-celluloseprepared IgG from eluate, trough filled with anti-NHS. (b) Bottom two wells contained NHS, trough filled with rabbit anti-eluate.

confirmed the results of McCormick et al. (20). Conjugates of antisera to IgG routinely stained the TBM. The staining was not seen in all villi, and the pattern was granular and smooth with some areas of TBM being more intensively stained than others. Anti-IgG conjugates also stained some areas of fibrinoid necrosis although the bulk of the fluorescence in each microscopic field was due to TBM staining. The eluates stained homologous placentas but did not stain basement membranes of lung, thyroid, or kidney.

\section{Immunochemical studies}

\section{Qualitative Studies of Eluate}

Immunoelectrophoresis of placental eluates against anti-NHS revealed IgG precipitation with occasional eluates giving bands of precipitation about the well and rarely in the beta region (Fig. 1a). Results of doublediffusion Ouchterlony analysis are given in Table I. The addition of $3 \%$ PEG to agar did not change the number of positive results for any of the antisera except fibrinogen. In this case, the number of positive samples was changed from 40 to $100 \%$. Ouchterlony analysis generally confirmed the results obtained by immunofluorescence and precipitation was never observed when eluate was diffused against serum from the mother, pooled adult or fetal sera, or Cohn fraction II.

\section{Quantitative Studies of Eluate}

The amount of IgG in placental eluates varied from 1.26 to $6.07 \mathrm{mg} / \mathrm{ml}$ and the yields per placenta ranged from 17.25 to $63.57 \mathrm{mg}$. The average value for $\mathrm{IgG}$ for all eluates was $3.78 \mathrm{mg} / \mathrm{ml}$, and the average placenta yielded $32.44 \mathrm{mg}$. Since the bulk of fluorescence in the immunohistological studies was due to TBM-IgG, the
TABLE I

Double-radial Diffusion of Placental Eluate Against Antisera and Other Human Sera

\begin{tabular}{lc}
\multicolumn{1}{c}{ Serum } & $\%$ Positive \\
\hline Anti-IgG & 100 \\
Anti-IgA & 85 \\
Anti-IgM & 10 \\
Anti-fibrinogen & 40 \\
Other* & 0 \\
\hline
\end{tabular}

* Negative results were obtained with antisera to $\operatorname{IgE}, \operatorname{IgD}$, C3, and C3 proactivator. Also, eluate did not precipitate, either with or without PEG, when diffused against maternal sera, pooled adult sera, pooled neonatal sera, or Cohn fraction II. 20 eluates were tested.

IgG eluted from placenta can be assumed to have come from TBM, and will hereafter be called "eluate-IgG."

Single-radial diffusion analysis were done in parallel for $\operatorname{IgG}, \operatorname{IgA}$, and $\operatorname{IgM}$ in paired mother and baby samples with eluate prepared from the placenta of each pregnancy and the results are presented in Table II. These results tend to confirm those obtained by immunofluorescence and Ouchterlony analysis in that IgG was the predominant Ig in eluates, small amounts of $\operatorname{IgA}$ were present, and IgM was undetectable. These results suggest that placental eluate is of maternal origin in so far as IgM is present in cord sera and absent in eluates, and $\operatorname{IgA}$ is absent from cord sera and present in eluates. This impression was confirmed by $\mathrm{Gm}$ and Inv typing of four mother-eluate pairs in that the same immunogenetical markers were found in the maternal sera and in the eluates. Another experiment in which IgG subclass determination were performed on all 20 sets of mother-babyeluate samplts failed to show a significant difference in subclasses within each set (25).

\section{Search for Immune Complexes in Eluate}

IgG prepared by DEAE-cellulose chromatography of placental eluate was used to immunize two rabbits, and

TABLE II

Quantitative Immunoglobulins in Mother and Baby Sera and Placental Eluates

\begin{tabular}{cccc}
\hline Ig values* & Mothers & Babies & $\begin{array}{c}\text { Placental } \\
\text { eluates }\end{array}$ \\
\hline IgG & 115.60 & 143.10 & 23.60 \\
& \pm 22.32 & \pm 24.39 & \pm 28.14 \\
IgM & 141.30 & 13.10 & 0 \\
& \pm 34.15 & \pm 4.07 & 0 \\
IgA & 145.90 & 0 & 3.05 \\
& \pm 63.70 & 0 & \pm 2.82 \\
\hline
\end{tabular}

* All values in WHO units per milliliter (mean \pm SEM). 20 mother, baby, and placental eluate sets studied.

Immunological Studies of Human Placenta 
antisera from these animals were used in an immunoelectrophoretical analysis of pooled NHS. The rabbit anti-eluate-IgG only recognized $\mathrm{IgG}$ in human serum (Fig. 1b), suggesting that the IgG used for immunization was not complexed with an antigen either recognizable by the rabbits and/or not present in pooled NHS.

The solubility of immune complexes in certain concentrations of PEG is less than that of comparable amounts of $\operatorname{IgG}(33,36)$. The solubility of $\left[{ }^{125} \mathrm{I}\right] \operatorname{IgG}$ placental eluate in PEG was thus compared to that of radioiodinated IgG prepared by DEAE-cellulose chromatography from NHS, the same IgG treated at elution conditions, iodinated rabbit $\mathrm{IgG}$, and labeled rabbit complexes of human IgG-anti-IgG in antigen excess.

Placental eluate-IgG, NHS-IgG, NHS-IgG treated under elution conditions, and rabbit IgG were soluble in 7.5\% PEG, whereas the radiolabeled rabbit immune complexes were not, again suggesting that eluate-IgG probably was not complexed with antigen.

\section{Immunobiological studies}

\section{Search for Anti-HL-A Activity in Eluates}

Eluate-IgG showed no specificity for lymphocytes, erythrocytes, or platelets by either direct or indirect immunofluorescence. All eluates gave negative results when tested for lymphocytotoxicity by using a panel of 30 normal lymphocytes. Five eluates tested for cytotoxicity by using lymphocytes from the children's parents gave negative results, and IgG-eluates did not block the cytotoxicity of anti-HL-A sera that were specific for the parent's cells. IgG placental eluates were additionally noncytotoxic for (a) lymphocytes from patients with chronic lymphocytic leukemia, and (b) PHA-transformed lymphocytes. A parallel experiment employed an anti-HL-A2 serum that had been subjected to elution conditions, and this serum showed no loss of activity for HL-A2, suggesting that anti-HL-A activity was not destroyed in the eluates during the elution procedure. The eluates were further tested by the LALI assay, in order to detect a possible lymphocyte-dependent antibody activity. No anti-HL-A antibody could be demonstrated. These experiments imply that placental eluate does not have anti-HL-A specificity. This impression is further strengthened by the observation that all 20 sets of mother-baby-eluate samples were screened by the Eurotransplant HL-A computerized program in the Netherlands for anti-HL-A antibodies by using both cytotoxic and agglutination tests, and, although occasional weak reactions were reported, they did not show any significant correlations with the known HL-A antigens.

\section{Inhibition by Eluate of Various Lymphocyte Culture Systems}

O. T. Placental eluates and IgG prepared from placental eluates effectively inhibit the blastogenic effect of O. T. on human lymphocytes in vitro (Table III). Even though IgG prepared from AB serum exerts a measurable inhibition in this system, the effect can be dilutedout while eluate and eluate-IgG are still strongly inhibitory. The mechanism of the inhibition of lymphocyte stimulation by $\mathrm{O}$. T. with NSH-IgG is probably nonimmunological, and suggests that other nonimmunological inhibitors of the blastogenic reaction may be found in human sera. Indeed, several inhibitors are present in placental eluate, because reactions obtained by stepwise elution of pooled eluates from DEAE-cellulose using $\mathrm{pH}$ 8.0 phosphate buffers of molarity $0.01,0.05$, and 1.00 still contained some inhibitory activity in the $1.00 \mathrm{M}$ fraction. The nature of these later eluting eluates was not studied, but they were thought to represent gammaglobulins of altered charge due to acid hydrolysis during the acid conditions of the elution procedure.

$P H A$. Placental eluates and IgG prepared from placental eluates effectively inhibited the mitogenic effect of PHA on human lymphocytes in vitro, as seen in Fig. 2.

TABLE III

Inhibition of $O . T$. Responses In Vitro

\begin{tabular}{|c|c|c|c|c|c|c|c|c|}
\hline \multicolumn{3}{|c|}{ Eluate } & \multicolumn{3}{|c|}{ Eluate-IgG } & \multicolumn{3}{|c|}{ NHS-IgG } \\
\hline Amount & cpm & $\begin{array}{c}\% \\
\text { Inhibition }\end{array}$ & Amount & cpm & $\begin{array}{c}\% \\
\text { Inhibition }\end{array}$ & Amount & $\mathrm{cpm}$ & $\begin{array}{c}\% \\
\text { Inhibition }\end{array}$ \\
\hline$\mu g$ & & & $\mu g$ & & & $\mu g$ & & \\
\hline 70 & 3,911 & 96 & 75 & 1,923 & 98 & 55 & 17,302 & 69 \\
\hline 35.00 & 6,620 & 93 & 37.50 & 8,371 & 92 & 27.50 & 42,808 & 23 \\
\hline 17.50 & 9,775 & 90 & 18.75 & 14,694 & 95 & 13.75 & 48,988 & 12 \\
\hline 8.75 & 17,182 & 82 & 9.37 & 17,328 & 82 & 6.87 & 46,805 & 16 \\
\hline 4.37 & 26,618 & 72 & 4.68 & 31,448 & 67 & 3.43 & 54,041 & 3 \\
\hline
\end{tabular}

These data represent results obtained from one set of experiments using placental eluate, IgG prepared from that eluate, responding lymphocytes from an unrelated donor, and NHS known to be devoid of anti-HL-A. They are representative of 12 sets of experiments using 12 different placental eluates and unrelated-donor lymphocytes. 


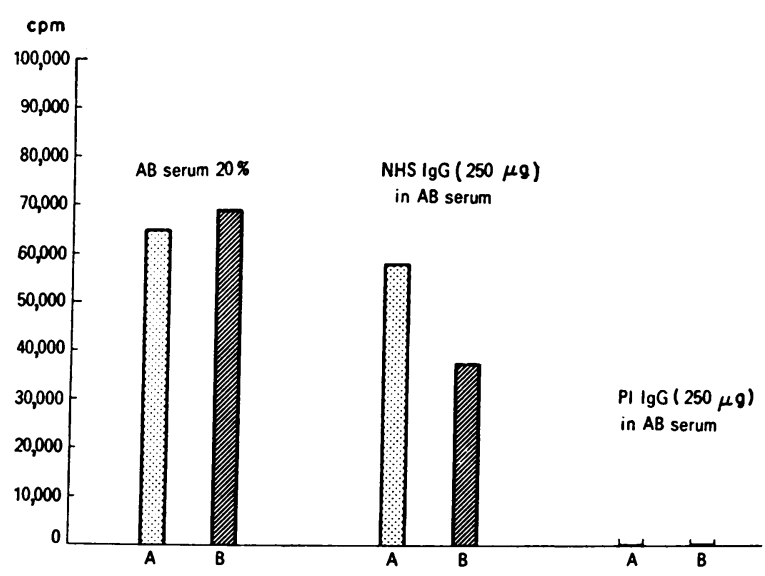

Figure 2 Effect of NHS-IgG and placental eluate IgG on homologous lymphocyte responses to phytohemagglutinin. "Pl IgG" signifies IgG prepared from placental eluate by DEAE-cellulose chromatography. "A" and " $\mathrm{B}$ " indicate different lots of cells. Eluate- or NHS-IgG in culture for entire period.

An inhibitory effect with both NHS and IgG prepared from NHS was repeatedly observed, but this "nonspecific" inhibition was several orders of magnitude less than that caused by eluate-IgG. The spontaneous uptake of tritiated thymidine by human blood lymphocytes in the absence of stimulation was $592 \mathrm{cpm} \pm$ SEM of 140 . In the presence of $125 \mu \mathrm{g} / \mathrm{ml}$ of NHS-IgG the spontaneous uptake was $574 \pm 157$, and in the presence of $125 \mu \mathrm{g}$ of eluate-IgG it was $155 \pm 10$. This suggests that the inhibitor in NHS-IgG is less effective than eluate-IgG against unstimulated as well as stimulated lymphocytes, again implying that the inhibitors in NHS are nonspecific.

$M L C$. Placental eluates and eluate-IgG effectively inhibited the one-way MLC reaction, as seen in Fig. 3. In this case the inhibitory effect of NHS-IgG was less than that observed in the PHA system. The "nonspecific" inhibitory effect of NHS-IgG compared to parallel concentrations of eluate-IgG in the two-way MLC reaction was minimal at $125 \mu \mathrm{g}$ concentrations of $\mathrm{IgG}$ as determined by the results of a dose-response experiment which are presented in Fig. 4.

As in the O. T. system, fractions of eluate obtained by stepwise elution of pooled eluates obtained from DEAE-cellulose chromatography still contained some inhibitory activity in the $1.00 \mathrm{M}$ fraction, but inhibition was again less in the MLC than in the O. T. system (viz, using $11.2 \mu \mathrm{g}$ of protein, $80.8 \%$ inhibition in the O. T. system and only $21.6 \%$ inhibition in MLC). Thus the effect of "nonspecific" serum inhibitors seems to be less marked in MLC than in either O. T. or PHA. The MLC responses of all pairs of unrelated lymphocytes tested so far were found to be inhibited by individual eluates, without apparent specificity.

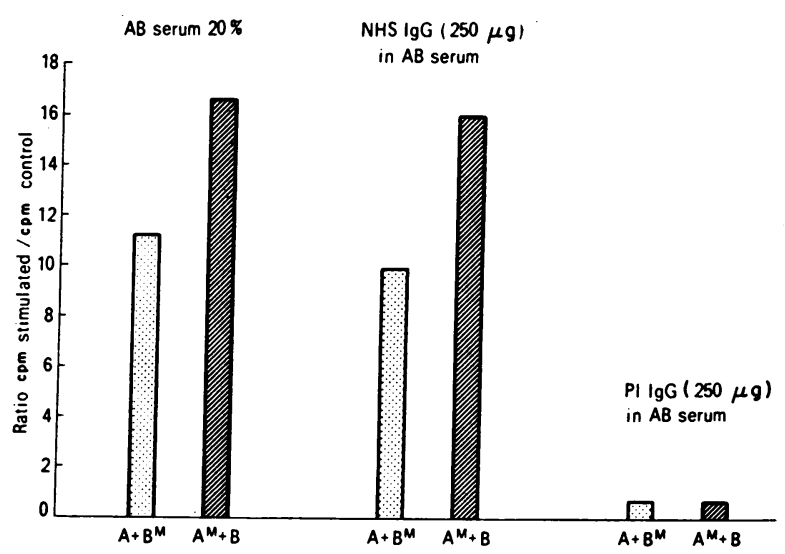

Figure 3 Effects of NHS-IgG and placental eluate IgG on homologous lymphocyte responses in the mixed lymphocyte culture reaction. "P1 IgG" signifies IgG prepared from placental eluate by DEAE-cellulose chromatography. "A" and " $B$ " indicate different lots of cells, and " $A$ " or " $B$ " indicate stimulator cells that have been treated with mitomycin.

Some studies of the mechanism of MLC inhibition by eluate-IgG was undertaken. We were unable to inhibit the two-way MLC reaction with either $250 \mu \mathrm{g}$ of heataggregated IgG or with human DNA-anti-DNA immune complexes in antigen excess prepared from a patient with lupus erythematosis, suggesting that the inhibition by eluate-IgG was not due to aggregate or immune-complexes. $F\left(a b^{\prime}\right)_{2}$ fragments were prepared from eluate-

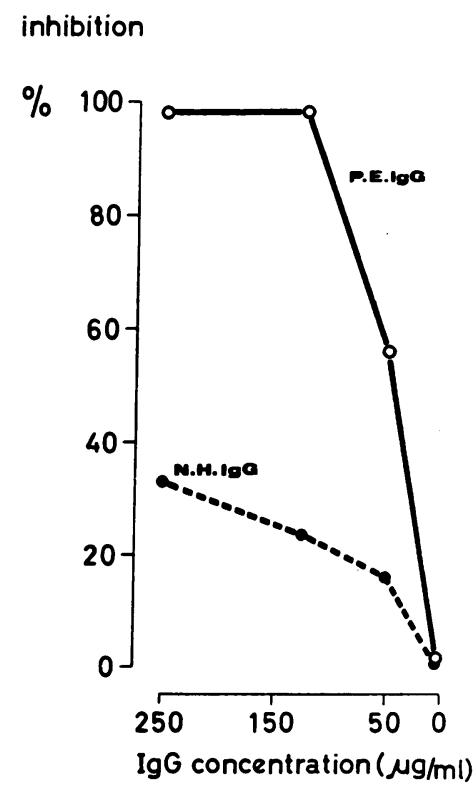

FIGURE 4 Dose-response inhibition curves of two-way MLC with IgG from placental eluates and serum. P.E. IgG is IgG prepared from placental eluate, and N.H. IgG is IgG prepared from NHS.

Immunological Studies of Human Placenta 
TABLE IV

Inhibition of $M L C$ with $F\left(a b^{\prime}\right)_{2}$ Fragments of Eluate-IgG

\begin{tabular}{lccc}
\hline Material added* & $\begin{array}{c}\text { One-way } \\
\text { MLC }\end{array}$ & $\begin{array}{c}\text { Two-way } \\
\text { MLC }\end{array}$ & $\begin{array}{c}\text { Back- } \\
\text { ground }\end{array}$ \\
\hline \multirow{3}{*}{ Nothing } & \multicolumn{4}{c}{ cpm } \\
& 5,833 & 7,623 & 692 \\
Serum $\mathrm{F}\left(\mathrm{ab}^{\prime}\right)_{2}$ & 1,019 & 2,978 & 354 \\
& & & $(2.6)$ \\
Nothing & 4,868 & 5,146 & 595 \\
& $(11.8)$ & $(8.2)$ & $(2.6)$ \\
Eluate $\mathrm{F}\left(\mathrm{ab}^{\prime}\right)_{2}$ & 412 & 630 & 233 \\
\hline
\end{tabular}

* $250 \mu \mathrm{g}$ protein. Numbers in parentheses are ratios of nothing added over respective $F\left(a b^{\prime}\right)_{2}$ fractions.

IgG in order to see if MLC inhibition was Fc mediated, and the results of this experiment indicated that $250 \mu \mathrm{g}$ of eluate-IgG fragments inhibited both the one-way and the two-way MLC reactions more effectively than did $\mathrm{F}\left(\mathrm{ab}^{\prime}\right)_{\text {a }}$ prepared from NHS-IgG (Table IV). In this experiment the inhibition of spontaneous uptake by NHS-IgG and eluate-IgG fragments were remarkably similar, suggesting that the inhibition of spontaneous uptake of DNA precursors by human lymphocytes in vitro may be due to a different mechanism than that responsible for MLC inhibition.

Finally, the binding of eluate-IgG to its target in MLC reactions was investigated by incubating $250 \mu \mathrm{g}$ of NHS-IgG and eluate-IgG with lymphocytes, this was followed by two washes in buffered physiological saline and study of the incubated and washed cells in the MLC reaction. The results of this experiment suggested that the binding is not very tight, although the inhibition was again considerably in excess of that obtained with NHSIgG, as seen in Fig. 5. Loose binding may account for the negative results obtained in the immunofluorescence
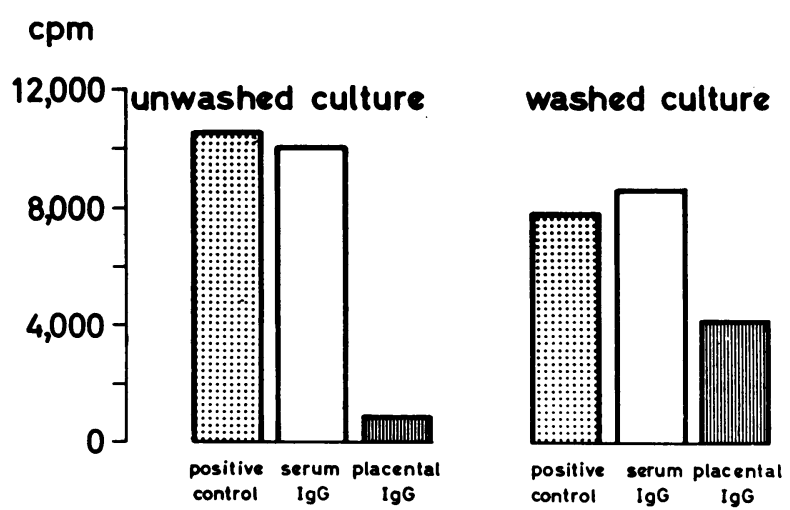

FIGURE 5 Effects of washing on inhibition of MLC by placental IgG. Two-way MLC reaction. Lymphocytes incubated with $250 \mu \mathrm{g} \operatorname{IgG}$ for $1 \mathrm{~h}$ at $37^{\circ} \mathrm{C}$ and washed twice in buffered physiological saline. experiments using eluate and lymphocytes. Alternatively, eluate specificity may be directed toward a lymphocyte product, or, if there is specificity for a receptor on lymphocytes, the eluate-receptor complex may be released from the cell membrane. The role, if any, of monocytes and/or macrophages in this system has not been studied.

\section{DISCUSSION}

Immunohistological studies have shown the presence of IgG on the TBM of all placentas we have studied, and McCormick et al. (20) found IgG, complement, and fibrinogen on TBM as early as the 10th wk of gestation. The staining is probably not due to maternal proteins trapped within placentas during delivery, because these would wash free during perfusion or during washings of the cryostat sections during the staining procedure. Also, trapping would have probably involved albumin, and we have not found positive staining for albumin.

FITC-eluate-IgG specifically stains TBM of autologous and homologous placentas. The antigen does not seem to be basement membrane because eluate does not stain basement membranes of the lung, thyroid, or kidney. Eluate does not contain maternal IgG trapped during passive transit through TBM en route from mother to fetus, because proteins that were not immunologically fixed to TBM would have been washed free during the extensive PBS washings that preceed acid elution.

Characterization of eluate indicates that it is predominantly IgG, although small amounts of $\mathrm{IgA}$ are commonly found, and smaller amounts of $\operatorname{IgM}$ are occasionally identified. The frequent occurrence of $\operatorname{IgA}$ suggests that eluate is of maternal origin, and this is supported by the presence of identical $\mathrm{Gm}$ types in paired samples of maternal serum with placental eluates. Immune complexes are thought to not be present in eluates as judged by eluate solubility in PEG, by the observation that antisera obtained from rabbits immunized with eluate-IgG produce antisera that react only with IgG in NHS, and by the observation that human DNA-anti-DNA complexes did not inhibit MLC.

Eluate-IgG does not recognize human lymphocytes as judged by immunofluorescence experiments. Also, none of our eluates gave lymphocytotoxic or lymphocytoagglutinin reactions that could be significantly attributed to anti-HL-A activity. We were additionally unable to demonstrate lymphocytotoxic activity in five eluates for the lymphocytes of their parents. Some of our eluates did give cytotoxic and/or agglutination reactions, but none of these could be attributed to any of the known HL-A antigens. Some of these reactions may be due to antibody to unspecified antigens on lymphocytes. None of our eluates recognized lymphocytes from patients with chronic lymphocytic leukemia, nor did they recognize blast cells obtained by culture of lymphocytes with PHA. 
Our experiments show that eluate-IgG effectively inhibits lymphocyte responses to O. T., PHA, and MLC reactions. Inhibition can be brought about with relatively small amounts of eluate-IgG, and the capacity to inhibit blastogenic responses of lymphocytes in vitro is very much greater with eluate-IgG than with either NHS or NHS-IgG. The "nonspecific" inhibitors of blastogenic responses are diluted from solution at relatively low titers, and they do not seem to exert much of an effect below $125 \mu \mathrm{g} / \mathrm{ml}$. It would seem to be most hazardous to enter into a study of inhibitors of lymphocyte test systems in vitro without biochemically characterizing the inhibitors as well as other possible "nonspecific" inhibitors that might be present. We accept reports of undefined inhibitors in unfractionated serum with considerable circumspection.

Inhibition of the MLC reaction was not specific for parental lymphocytes, and most eluates seemed to inhibit most lymphocytes. The inhibitory effect was partially removed by washing the cells after incubation with eluate before placing them into culture. $F\left(a b^{\prime}\right)_{2}$ fragments of eluate-IgG retained its capacity to quantitatively inhibit more effectively than similar fragments from NHSIgG, suggesting that the inhibition is immunological.

The inhibition of blastogenic responses of lymphocytes by eluate-IgG does not seem to be due to anti-HL-A, but the eluate-IgG may be directed against a non-HL-A site such as the MLC locus $(37,38)$ or recognition structures (39). It is possible that the specificity for eluateIgG is a "trophoblast antigen" that is shared by lymphocytes, and that the inhibition of blastogenesis in vitro is caused by a cross-reaction between eluate-IgG and lymphocytes. Evidence for cross-reacting antigens between trophoblasts and lymphocytes in the rat has been presented by Beer, Billingham, and Yang (17). Lymphocyte-trophoblast cross-reactions may partially account for the frequent occurrence of antilymphocyte activity in postpartum sera (40).

In conclusion we suggest that the presence of $\operatorname{IgG}$ on TBM is not without biological significance in the maternofetal relationship. The placenta is a lifeline for the foetus. It is of fetal origin and is presumably endowed with paternal as well as maternal gene products. If the mother responds to some of these products as antigens it is likely that she will reject the placental graft. CMI mechanisms are generally responsible for graft rejections, and these can sometimes be effectively blocked by blocking antibodies (41). IgG on TBM may represent maternal blocking antibodies that protect the placenta from maternal CMI. The antigen responsible for the hypothesized maternal blocking antibody may be specific for trophoblast or possibly the product of the MLC or Ir loci on lymphocytes. The blocking characteristics of maternal antibody could be determined by the physical chemistry of the trophoblast or lymphocyte antigen, analogous to the concept that antigenic density is an important determinant for the presence of complementfixing antibodies (42). If this is true, it could introduce two novel mechanisms leading to fetal wastage: (a) some women may mount an aberrant response to "trophoblast antigen" by producing nonblocking antibodies, analogous to the antibodies that some patients with clinical allergy produce to antigens such as ragweed (43); and $(b)$ some trophoblasts may have a metabolic abnormality that causes them to produce "trophoblast antigen" whose physical chemistry is not appropriate to invoke blocking antibodies in the mother. The idea of trophoblast-specific antigens is not new to immunobiology (3, 44,45 ), but the concept of aberrant responses to these antigens or of the production of aberrant antigens has not been hitherto considered, and this may merit further consideration.

\section{ACKNOWLEDGMENTS}

We thank Dr. E. van Loghem, Immunogenetics Unit, Central Laboratory of the Netherlands Red Cross Blood Transfusion Service, Amsterdam, for performing the $\mathrm{Gm}$ and Inv typing. Dr. R. Axford of the University College of North Wales, Bangor, assisted in the preparation of some of the sheep antisera. We are most appreciative for the advice of Prof. J. van Rood, University of Leiden, and particularly for his consent to test the sets of mother-babyeluate samples for anti-HL-A through Eurotransplant. Valuable technical assistance was provided by Liselotte Achermann and Karine Fournier, Geneva. Prof. R. Ceppellini of Turin and Basel, and Prof. P. A. Miescher of Geneva provided materials and support that made this work possible, and useful criticisms of the work were obtained from H. C. Goodman and P. H. Lambert in Geneva, H. H. Fudenberg in San Francisco, and J. N. McCormick, Edinburgh.

This study was supported by the Swiss National Fund for Scientific Research grant 3.8580.72 and 3.617.71SR and the CNR Centre Immunogenetica e Istocompatibilità. Much of this work was done in the WHO Laboratory, Haematology Division, Department of Medicine, University of Geneva School of Medicine, Switzerland.

\section{REFERENCES}

1. Billingham, R. E. 1964. Transplantation immunity and the maternal-foetal relation. N. Engl. J. Med. 270: 667672.

2. Medawar, P. B. 1953. Some immunological and endocrinological problems raised by evolution of vivparity in vertebrates. Symp. Soc. Exp. Biol. 7: 320-338.

3. Beer, A. E., and R. E. Billingham. 1971. Immunobiology of mammalian reproduction. Adv. Immunol. 14: $1-84$.

4. Fudenberg, H. H., and B. R. Fudenberg. 1964. Antibody to hereditary human gamma-globulin $(\mathrm{Gm})$ factor resulting from maternal-fetal incompatibility. Science (Wash. D. C.). 145: 170-171.

Immunological Studies of Human Placenta 
5. Faulk, W. P., E. van Loghem, and G. B. Stickler. 1974. Maternal antibody to foetal light-chain (Inv) antigens. Am. J. Med. 56: 393.

6. Rocklin, R. E., J. E. Zuckerman, E. Alpert, and J. R. David. 1973. Effect of multiparity on human maternal hypersensitivity to foetal antigen. Nature (Lond.). 241: 130-131.

7. Youtananukorn, V., and P. Matangkasombut. 1972. Humen maternal cell mediated immune reaction to placental antigens. Clin. Exp. Immunol. 11: 549-556.

8. Purtito, D. T., H. M. Hallgren, and E. J. Yunis. 1972. Depressed maternal lymphocyte response to phytohaemagglutinin in human pregnancy. Lancet. 1: 769-771.

9. Campion, P. D., and H. L. F. Currey. 1972. Cellmediated immunity in pregnancy. Lancet. 2: 830.

10. Ceppellini, R., G. D. Bonnard, F. Coppo, V. C. Miggiano, M. Popisil, E. S. Curtoni, and M. Pellegrino. 1971. Mixed leukocyte cultures and HL-A antigens. 1. Reactivity of young fetuses, newborns and mothers at delivery. Transplant. Proc. 3: 58-70.

11. Kasakura, S. 1971. A factor in maternal plasma during pregnancy that suppresses the reactivity of mixed leukocyte cultures. J. Immunol. 107: 1296-1301.

12. Buckley, R. H., R. I. Schiff, and D. B. Amos. 1972. Blocking of autologous and homologous leukocyte responses by human alloimmune plasmas: a possible in vitro correlate of enhancement. J. Immunol. 108: 34-44.

13. Ayoub, J., and S. Kasakura. 1971. In vitro response of foetal lymphocytes to PHA, and a plasma factor which suppresses the PHA response of adult lymphocytes. Clin. Exp. Immunol. 8: 427-434.

14. Riggio, R. R., J. E. Parrillo, Jr., F. G. Bull, G. H. Schwartz, K. H. Stenzel, and A. L. Rubin. 1971. Inhibition of lymphocyte transformation by a placental glycoprotein. Transplantation. 12: 400-401.

15. Youtananukorn, V., and P. Matangkasombut. 1973. Specific plasma factors blocking human maternal cellmediated immune reaction to placental antigens. Nat. New Biol. 242: 110-111.

16. Fox, H. 1971. Placental structure. In Scientific Basis of Obstetrics and Gynaecology. R. R. Macdonald, editor. The Williams \& Wilkins Company, Baltimore, Md. 87-113.

17. Beer, A. E., R. E. Billingham, and S. L. Yang. 1972. Further evidence concerning the autoantigenic status of the trophoblast. J. Exp. Med. 135: 1177-1184.

18. Loke, Y. W., V. C. Joysey, and R. Borland. 1971. HL-A antigens on human trophoblast cells. Nature (Lond.). 232: 403-404.

19. Bradbury, S., W. D. Billington, E. A. Williams, and D. R. S. Kirby. 1969. Surface mucin of human trophoblast. Am. J. Obstet. Gynecol. 104: 416-418.

20. McCormick, J. N., W. P. Faulk, H. Fox, and H. H. Fudenberg. 1971. Immunohistological and elution studies of the human placenta. J. Exp. Med. 133: 1-18.

21. Faulk, W. P., A. Carbonara, and M. Jeannet. 1971. Immunobiological studies on human placenta. In Immunology of Reproduction. K. Bratanor, R. G. Edwards, V. H. Vulchanov, V. Dikov, and B. Jomley, editors. Publishing House of the Bulgarian Academy of Sciences, Sofia.

22. Faulk, W. P. 1972. In Ontogeny of Acquired Immunity. R. Porter and J. Knight, editors. A Ciba Foundation Symposium. Elsevier Scientific Publishing Company, Amsterdam. 172-174.
23. Bonneau, M., M. Latour, J. P. Revillard, M. Robert, and J. Traeger. 1973. Blocking antibodies eluted from human placenta. Transplant. Proc. 5: 589-592.

24. Jeannet, M., W. P. Faulk, D. Crighton, and K. Fournier. 1973. Blocking of mixed lymphocyte cultures by IgG eluted from human placenta. In The Proceedings of the 8th Leucocyte Culture Conference. In press.

25. Faulk, W. P., M. Jeannet, W. D. Creighton, A. Carbonara, and F. Hay. 1974. Immunological studies of the human placenta. II. Characterization of immunoglobulins on the trophoblastic basement membranes. $J$. Reprod. Fertil. Suppl. 21. In press.

26. Hay, F. C., G. Torrigiani, and I. M. Roitt. 1972. The binding of human IgG subclasses to human monocytes. Eur. J. Immunol. 2 : 257-261.

27. Medical Research Council. 1966. Production of antibody against purified human G-globulin in rabbits, goats, sheep and horses. Immunology. 10: 271-279.

28. van Loghem, E., and L. Mårtensson. 1967. Genetic $(\mathrm{Gm})$ determinants of the ${ }_{2 c}(\mathrm{Vi})$ subclass of human IgG immunoglobulins: a study with special reference to $\mathrm{Gm}\left(\mathrm{C}^{3}\right)$ and $\mathrm{Gm}\left(\mathrm{C}^{5}\right)$ and their relationship with the $\mathrm{Gm}(\mathrm{b})$ determinants. Vox Sang. 13: 369-392.

29. Weir, D. M. 1967. Handbook of Experimental Immunology. Blackwell Scientific Publications, F. A. Davis Co., Philadelphia.

30. Clark, H. F., and C. C. Shepard. 1963. A dialysis technique for preparing fluorescent antibody. Virology. 20: 642-644.

31. McDivitt, H. D., J. H. Peters, L. W. Pollard, J. G. Harter, and A. H. Coons. 1963. Purification and analysis of fluorescein-labelled antisera by column chromatography. J. Immunol. 90: 634-642.

32. Faulk, W. P., and W. Hijmans. 1972. Recent developments in immunofluorescence. Prog. Allergy. 16: 9-39.

33. Creighton, W. D., P. H. Lambert, and P. A. Miescher 1973. Detection of antibodies and soluble antigen-antibody complexes by precipitation with polyethylene glycol. J. Immunol. 111: 1219-1227.

34. Bach, M. L., S. Solliday, and Strambuck. 1971. Detection of disparity in the mixed leucocyte culture test: a more rapid assay. In Histocompatibility Testing. 1970. Munksgaard, Copenhagen. 643-653.

35. Trinchieri, G., D. Bernoco, S. E. Curtoni, V. C. Miggiano, and R. Ceppellini. 1973. Cell-mediated lympholysis in man: relevance of HL-A antigens and antibodies. In Histocompatibility Testing. 1972. Munksgaard, Copenhagen. 509-519.

36. Harrington, J. C., J. W. Fenton, and J. H. Pert. 1971 Polymer-induced precipitation of antigen-antibody complexes: "Precipiplex" reactions. Immunochemistry. 8: 413-421.

37. Yunis, E. J., and D. B. Amos. 1972. Three closely linked genetic systems relevant to transplantation. Proc. Natl. Acad. Sci. U. S. A. 68: 3031-3035.

38. Eijsvoogel, V. P., J. J. van Rood, E. D. du Toit, and P. Th. A. Schellekens. 1972. Position of a locus determining mixed lymphocyte reaction distinct from the known HL-A loci. Eur. J. Immunol. 2: 413-418.

39. Ramseier, H., and J. Lindenman. 1972. Similarity of cellular recognition structures for histocompatibility antigens and of combining sites of corresponding alloantibodies. Eur. I. Immunol. 2: 109-114. 
40. Tongio, M. M., A. Berrebi, B. Pfeiffer, and S. Mayer. 1971. Serological studies on lymphocytotoxic antibodies in primiparous women. Tissue Antigens. 1: 243-257.

41. Hellström, K. E., and I. Hellström. 1970. Immunological enhancement as studied by cell culture techniques. Annu. Rev. Microbiol. 24 : 373-398.

42. Linscott, W. D. 1970. Effect of cell surface antigen density on immunological enhancement. Nature (Lond.). 228: 824-827.
43. Levine, B. B., R. H. Stember, and M. Fotino. 1972. Ragweed hay fever: genetic control and linkage to HL-A haplotypes. Science (Wash. D. C.). 178: 1201.

44. Hulka, J. F., and K. Mohr. 1968. Trophoblasts antigenicity demonstrated by altered challenge graft survival. Science (Wash. D. C.). 161: 696-698.

45. Kirby, D. R. S. 1968. The immunological consequences of extrauterine development of allogeneic mouse blastocytes. Transplantation. 6: 1005-1009. 